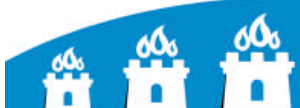 UCD DUBLIN (1) \\ UCD GEARY INSTITUTE DISCUSSION PAPER SERIES
}

\section{Mother's education and birth weight}

\author{
Arnaud Chevalier* \\ and \\ VINCENT O'SULLIVAN
}

June 122007

Draft 2.2

\begin{abstract}
:
Low birth weight has considerable short and long-term consequences and leads to high costs to the individual and society even in a developed economy. Low birth weight is partially a consequence of choices made by the mother pre- and during pregnancy. Thus policies affecting these choices could have large returns.

Using British data, maternal education is found to be positively correlated with birth weight. We identify a causal effect of education using the 1947 reform of the minimum school leaving age. Change in compulsory school leaving age has been previously used as an instrument, but has been criticised for mostly picking up time trends. Here, we demonstrate that the policy effects differ by social background and hence provide identification across cohorts but also within cohort. We find modest but heterogenous positive effects of maternal education on birth weight with an increase from the baseline weight ranging from $2 \%$ to $6 \%$.
\end{abstract}

\footnotetext{
* Arnaud Chevalier, Department of Economics, Royal Holloway, University of London, and Geary Institute, University College Dublin. Chevalier is also an associate at Centre for the Economics of Education, London School of Economics, and the Institute for the Study of Labour, IZA, Bonn. arnaud.chevalier@rhul.ac.uk

- Vincent O’Sullivan, Department of Economics, Warwick University and Geary Institute, University College Dublin, V.O-Sullivan@warwick.ac.uk
} 
Key words: Returns to education, health

JEL: I12, I29

\section{Acknowledgment:}

The data was made available by the Data Archive at Essex. We thank our colleagues at University of Kent, Royal Holloway and Geary Institute, as well as participants at presentations at the Institute of Education, St Gallen, Birmingham, Department of Work and Pension Economic Group (Kent), EALE meeting (Prague), and LoWER (Annecy) for comments that greatly improved this research. Special thanks to Tarja Viitanen and Gauthier Lanot for their comments on earlier drafts. All remaining errors are solely ours. 


\section{Introduction}

Whether birth weight is seen as an input in a health production function or an output, exposure to ill health at such a crucial stage in the physical development of a person is linked with increased infant mortality ${ }^{1}$ and serious short- and long-term effects (Case et al. 2005). Low birth weight, defined as weighting less than 2,500g (5lb 8oz), also lead to the transmission of inequality between generations (Currie and Moretti, 2005). The general wisdom is that policies increasing birth weight could have substantial returns. Thus, the World Bank has been financing programmes to improve maternal health, nutrition, and knowledge in developing countries (Tinker and Ransom, 2002). Even in the developed world, birth weight is an important policy objective. The US Department of Health has, for example, fixed a maximum of 5\% low birth weight objective in its Healthy People 2010 agenda.

The main non-genetic factors affecting birth weight are: gestation length, smoking, pre-natal health care, maternal nutrition (including alcohol and coffee consumption) and maternal stress. Maternal education can potentially affect all these inputs, and a correlation between birth weight and maternal education is a robust finding (Behrman and Wolfe, 1989, World Bank, 1993). Maternal education affects birth weight by improving the probability and/or productivity of health investment. Additionally, maternal education improves the financial resources available to the child directly and indirectly through the choice of partner, timing of fertility, and number of offspring (the quantity/quality trade off). The main agenda of this paper is to test whether the effect of maternal education on birth weight is causal or due to an unobserved third factor, such as the mother's discount rate affecting both her educational

\footnotetext{
${ }^{1}$ Post neonatal death rates are a non-linear function of birth weight, with the highest risk being observed for babies born at a weight between 1,500 and 1,999 grams (1.04\%) and the lowest for babies weighting more than 3,500 grams $(0.11 \%)$ (ONS, 2003). A large discontinuity is observed at 2,500 grams with mortality doubling compared to babies weighting between 2,500 and 3,000 grams.
} 
attainment, her health and subsequently the health of her child (Fuchs, 1982), in which case the estimated educational effect would be biased upwards.

The causal effect of maternal education on birth weight is identified by Currie and Moretti (2003) in the United States with a policy increasing the supply of colleges when the mother was a teenager. The rationale is that the opening of a college reduces the cost of higher education in a way that is uncorrelated with the unobservable term correlating both education and health. This identification allows them to conclude that maternal education has a causal effect on the use of prenatal care, improves marriage prospects, reduces smoking and ultimately reduces the incidence of low birth weight by 1 percentage point.

This paper assesses the impact of maternal education for a cohort of British mothers giving birth in the late Fifties. This period marked the heydays of the public provision of health services (the National Health Service was created in 1948) and as such, most children/mothers would have experienced similar medical technology and health-care information ${ }^{2}$. Moreover, all children are born in the same week in 1958. The identification stems from a legislative change creating a so called "natural experiment". In 1947, the minimum school leaving age was increased from 14 to 15 , generating an increase in maternal education independent of the mother's unobservable characteristics. A novelty of this paper is to improve on this common identification strategy. We document that the change in legislation affected children differently depending on their social background, with children from lower social class gaining the most. These differences in social background are themselves unrelated to birth weight. The difference in the effect of the policy by social background eliminates the criticism that the reform only captures a trend effect. We further provide robustness checks by

\footnotetext{
${ }^{2}$ An important decision made by mothers concerns the location of the delivery. The Royal College of Obstetricians and Gynaecologists recommended a target of $70 \%$ of mothers delivering in hospital. This was only reached in 1965. The Perinatal Mortality Survey (1958) was used to inform the debate on the effect of the location of delivery on birth outcomes but failed to reach any significant conclusions. (www.nhshisotry.net).
} 
estimating the model for population affected or not by the reform which support our assumption that the reform only increased the educational attainment of some groups. Moreover, we test that the reform is not just capturing some trends in education by generating two "fake reforms" around the change in school leaving age. These "fake reforms" are found to have no identification power.

This paper complements the analysis of Currie and Moretti (2003) in several dimensions. First it replicates their results to the UK at a different period in time when health care was rather homogenous, and medical knowledge and public information on health behaviour during pregnancy limited. Moreover, the negative consequences of smoking during pregnancy, the most important preventable factor of low birth weight, were not fully identified as a risk factor in the late Fifties ${ }^{3}$. So if the effects of education on health are mostly through differences in the use of health information, our estimates are likely to be lower than those found in Currie and Moretti. Second, the causal effect of education is identified for individuals with low level of education rather than at the upper end of the education distribution. If the health returns to education are decreasing with education, Currie and Moretti's estimates are potentially a lower bound. Finally, our dataset includes a richer set of controls, so that we can assess additional mechanisms by which maternal education impacts on birth weight.

For the 1958 cohort, one year of maternal education increases the average birth weight by 75 grams and reduces the probability of low birth weight by 2 percentage point. The later result is imprecise but larger than found by Currie and Moretti (2003), which could support the view that the returns to maternal education are decreasing with education. Contrary to the omitted variable bias intuition, the IV estimate is much larger than the OLS one. This

\footnotetext{
${ }^{3}$ The Surgeon General Advisory Committee and Smoking and Health first reported in 1964 and did not single out smoking during pregnancy as a specific health hazard. In the UK, Smoking and Health was published in 1962 by the Royal College of Physicians, ban on TV advertisement followed in 1965 (www.nhshistory.net).
} 
counter-intuitive result has been found in most studies identifying the effect of education on health with natural experiments (Grossman, 2006). The IV estimates identify the returns for the marginal individuals affected by the reform who may have larger returns that the mean individual. Indeed, we do provide evidence that the effect of maternal education on birth weight is heterogenous and reaches up to $220 \mathrm{~g}$ (or $6 \%$ increase from baseline) for the group most directly affected by the reform.

As in Currie and Moretti (2003) we find that maternal education affects the choice of partner (more educated, higher social class). However, we do not find evidence that the improvement in birth weight is due to a reduction in smoking behaviour or increased use of health services. These results are consistent with the fact that for these cohorts health care information, especially on the negative consequences of smoking during pregnancy, was scarce and the public provision of health care was rather homogenous. The effect of maternal education on birth weight remains even when pre-natal care and extensive family characteristics are included. Based on the mean effects, we calculate that a policy increasing maternal education has small social returns.

Despite the increase in educational attainment since 1958 our estimates are still pertinent since a substantial minority of individuals in the UK still leave schools at low levels of education ${ }^{4}$. Moreover, projects of reforming the minimum school leaving age are currently discussed so it is informative to assess the returns (financial and non-financial) of such

\footnotetext{
${ }^{4}$ Despite dramatic improvement in medical knowledge and technology, as well as ever increasing maternal education, low birth weight has remained stubbornly persistent in the Western world in the last three decades (National Centre for Health Statistics, 2003). Medical progress and maternal education have conflicting results on the average birth weight of children born. Following Currie and Moretti (2003) the positive trend in maternal education observed in the last three decades should have resulted in a reduction of the probability of low birth weight. However, medical progress has lead to a dramatic improvement in the survival of premature babies (really low birth weight have increased from 1.2\% to 1.4\% over the period 1970 2003), so that in England the probability of having a low birth weight baby is identical, at 7.9\% in 2003 and in 1970 (National Centre for Health Statistics, 2003). Also the increase in education has been associated with women having their first child at a later age, which may also increase the risk of low birth weight.
} 
policies. Finally, inference can be drawn for developing countries which may be facing levels of education and medical conditions that have some similarities with late Fifties Britain. The paper has the following structure: Section 2 describes the birth weight literature. Section 3 details estimation issues. The data is presented in Section 4 and the main results are discussed in Section 5. Section 6 adds some robustness checks and the last section concludes with further remarks.

\section{Birth weight, health and education, a review}

Low birth weight has costs to the individual and family but also to society. In the short-run, low birth weight babies faced increased mortality risks and larger health costs. Lewitt et al. (1995) estimate that $35 \%$ of all health care spending on new born children in the United States is related to low birth weight children who make up just under $8 \%$ of babies. Each additional gram costs $\$ 6$ to $\$ 10$ (Joyce, 1999) or up to $\$ 20$ (Almond et al. 2005) in additional health care. Low birth weight is also associated with reduced child development (Aylward et al. 1989, Hack et al. 1995), educational attainment (Corman \& Chaikind, 1998) and health. Lewitt et al. (1995), for example, calculate that low birth weight children incur additional annual costs of $\$ 1,500$ (in 1988) up to the age of 15 in terms of health care and education. Low birth weight is also negatively correlated with adult health, qualification and labour market attainment (Case et al, 2005, Currie and Hyson, 1999).

These correlations might simply reflect low investments of a mother not only in her own health whilst pregnant, but also in the child post-natal environment, health and human capital, leading to the adverse outcomes aforementioned. Alternatively, Wilcox and Russell (1983) and Wilcox (2001) argue that the correlation between low birth weight and bad health is due to (unobservable) biological processes that affect both weight and health or that "infants at 
biological risk may be more susceptible to adverse environmental risk than are normal babies". Hence, a policy increasing birth weight would have no effect on reducing the negative outcomes currently associated with low birth weight. The question of causality of low birth weight on these outcomes is a debated topic. Almond et al. (2005) dispute the causality of low birth weight on health costs and infant mortality by comparing these outcomes for twins, and thus differencing out any genetic and family effects. They find that between-twin birth weight differences have only a small impact on hospital cost differentials. However, Black et al. (2007) estimate substantial between-twin differentials on adult outcomes (height, IQ, education and wage), while Currie and Moretti (2005) find evidence of inter-generational transmission of low birth weight. This controversy can be reconciled if the negative consequences of low birth weights are compounded over time.

Whilst the debate on the causality of birth weight on these outcomes is clearly of importance to design the appropriate policies, the objective of this paper is to concentrate on the causes of low birth weight rather than its consequences. As well as genetics, gestation period and foetal growth are the main drivers of birth weight. The medical research has identified certain risk factors which affect the gestation period and/or the foetal growth; these include nutrition during pregnancy including consumption of alcohol or coffee, time elapsed before prenatal medical care, frequency of visits during pregnancy, and physical and emotional stress during pregnancy. Moreover, the most important preventable risk factor is smoking during pregnancy. Since all these factors are within the control of the mothers, improving maternal education can been seen as a potential instrument to improve birth weight.

First, more educated mothers face a more favourable budget constraint either directly through increased earnings or indirectly through assortative mating. Additionally, education may modify the budget constraint by its effect on fertility decision: timing and number of 
children so that more educated mothers would have more resources per child. Hence, maternal education may simply proxy for an income effect. Second, maternal education affects maternal health, which determines her reproductive capacity and her ability to physically cope with pregnancy. The causal effect of education on health may also be through productive efficiency (Grossman, 1975) i.e. more educated people are more efficient producers of health - or allocative efficiency where education increases the ability to process and use "medical" information (Welch, 1970 or Michael, 1973). Note also that the opportunity costs of bad health are higher for more educated individuals. Education thus leads to a better input-mix as it increases the willingness and ability of individuals to change their preventive health behaviour (Kenkel, 1991), seek out advice and information, and awareness of health technology improvement (Lleras-Muney \& Lichtenberg, 2006). However the relationship between education and health may be spurious. Fuchs (1982) for example, argue that since both education and health can be seen as component of the individual's capital, they both depend on individual's characteristics. For example an individual with a high discount rate will invest less in his education and his own health ${ }^{5}$. However, one could argue that education has a positive feedback on discount rate, so that the relationship between education and health may, to some degree, still be causal (Becker \& Mulligan, 1997).

An extensive review of the literature on education and health is available in Grossman (2006) and supports the view that the effect of education on health is causal. Contrary to the omitted variable hypothesis, IV estimates are in general larger than estimates assuming the exogeneity of education. However, as in the literature on the financial returns to education, the IV estimates can be seen as local average treatment effects for the marginal individuals affected by reforms.

\footnotetext{
5 Munashinge and Sicherman (2000) provide empirical evidence linking high discount rates and unhealthy behaviour such as smoking.
} 
Numerous works include maternal education in either birth outcomes or prenatal input equations as a control, but not much attention has been paid to the causality of maternal education on birth weight. Desai and Alva (1998) and Thomas et al. (1991) test the causality for developing countries and Currie and Moretti (2003) is the first paper investigating the issue for a developed country. Using 30 years of Vital Statistics Natality, a register of all the births in the United States, Currie and Moretti (2003) use college proximity as an instrument for maternal education. They find that one year of maternal education reduces both the probabilities of low birth weight and premature birth by 1 percentage point. These outcomes could be due to changes in the following behaviour: maternal education reduces smoking during pregnancy (-6 percentage points), and increase pre-natal care $(+2.5)$ and partnership $(+1.3)$. The authors thus conclude that education improves infant health through a number of different pathways. For the UK two recent papers have used change in school leaving age to assess the effect of maternal education on child health. Doyle et al. (2005) uses the 1997-2002 Health Survey of England and identify the effects of parental education and income on selfreported child health. Parental education is instrumented by the 1973 change in school leaving age as well as grand-parents smoking behaviour. However, for their sample, the reform is only a valid instrument for paternal education; they then report a significant effect of father's education on the health of teenage boys only. Lindeboom et al (2006) relies on the National Child Development Study and the 1947 educational reform as in this study - but without differentiating by social class. They estimate the effects of parental education on several health outcomes by discontinuity design, but find little support for a causal effect. Overall evidence on the causal effect of parental education on child health is thus mixed. 


\section{Estimation issues}

Birth weight is a function of embryo's and mother's characteristics, maternal health ${ }^{6}$ and prenatal care. Prenatal care can be seen as a complement or substitute for maternal health in the production of child health and is potentially endogenous ${ }^{7}$. Additionally, prenatal health behaviours such as smoking may also be biased: for example mothers who smoke (observed in the dataset) may also drink (not observed in the data set) ${ }^{8}$.

It is debatable as to whether education enters the birth weight production function directly or indirectly through the other parameters. For instance, Rosenzweig and Schultz (1983) argue that parental education affects the choice of health inputs but has no direct effect on birth weight. Contrary to this, Joyce (1994) finds that education belongs in both the input demand function and the birth weight production function. Treating maternal education as exogenous is also unsatisfactory. As discussed above, maternal education, the main variable of interest, is affected by unobservable characteristics also correlated with prenatal inputs and birth weight.

More generally, all variables measured after the mother has completed her education can also be considered endogenous. Thus, most of our attention is focused on reduced form models which identify the total effect of maternal education on birth weight. Three additional

\footnotetext{
${ }^{6}$ There is selection bias if mothers in bad health do not have children. These problems are neglected here.

${ }^{7}$ As the researcher does not have full information about the mother's health endowment, there will always be unobservable characteristics affecting both the choice of prenatal care as well as the infant health (Rosenzweig and Schultz, 1983). For example, those with worse health seek prenatal care earlier and/or more often than others leading to underestimating the effect of prenatal care on birth weight. Alternatively favourable selection may exist: healthier people use more prenatal inputs (as using prenatal care is but one form of healthy behaviour). For instance Grossman and Joyce (1990) find that healthier women start pre-natal care earlier. Favourable selection results in overestimating the effect of prenatal care on birth weight.

${ }^{8}$ Evans and Ringel (1999) use variation in cigarette taxes between States as an instrument and find the causal effect of smoking and report that smoking during pregnancy reduces birth weight by between $238 \mathrm{~g}$ and $253 \mathrm{~g}$. Using data where mothers who smoked prior to pregnancy were randomly assigned counselling, Sexton and Hebel (1984) found a negative effect of roughly $92 \mathrm{~g}$ on birth weight.
} 
reduced forms are considered including gestation period, body mass index as a proxy of maternal health, and pre-pregnancy smoking behaviour as a proxy for discount rate. The base model includes only dummies for the cohort of birth of the mother, mother's social class (measured by the social class of her father), region of residence in 1958, maternal education, child's gender and parity.

$$
\begin{aligned}
\text { Outcome } & =\alpha E+\beta O+\delta Z+\rho F B+\gamma X+\varepsilon \\
E & =\phi_{1} S L A+\phi_{2} S L A * F B+f(Z, X)+\mu
\end{aligned}
$$

Where the outcome in equation (1) is either infant health or prenatal inputs. $E, O$ and $Z$ represent maternal education, obstetrical information (gender of child, parity, and, in some models, gestation period which is potentially endogenous), and demographic controls (age of mother, region of residence) respectively. $F B$ is a measure of the mother's family background as she was growing up (maternal grand-father social class) and $X$ is a set of potentially endogenous inputs which is omitted in most models and $\mu$ and $\varepsilon$ are error terms. SLA is the school reform of 1947 which first affected the cohort of children born in the later part of 1933.

The identification strategy relies on a schooling reform that creates an exogenous change in maternal education. As well as increasing compulsory schooling by one year, the 1944 Education Act introduced a wide range of educational reforms (e.g. free for-all secondary education, expansion in the numbers of teachers and free milk and meals) reducing the cost of education in England and Wales for the poorest families ${ }^{9}$. The Raising of the School Leaving Age (RoSLA) from 14 to 15 was a partial implementation of an original proposal to raise the school leaving age to 16 (this was delayed until 1973). The first cohorts affected by the reform were those born after August 1933 in England and Wales, and August1934 in Scotland. Figure 1 reports the evolution of educational attainment through time after controlling for region. It

\footnotetext{
${ }^{9}$ For Scotland and Northern Ireland separate legislations to the same effect were passed in 1945 and 1947 respectively. Our dataset does not include data for Northern Ireland. Due to the small time difference and small sample size, we cannot use the discrepancy between Scotland and the rest of Britain so implement a difference in difference estimate. See Jones (2003) for further details in his historical view of education in Britain.
} 
clearly shows the discontinuity in attainment for mothers born after 1933 for whom schooling increased by 9 months on average ${ }^{10}$. Moreover, Galindo-Rueda (2003), and Chevalier et al. (2004) for a subsequent reform, show that increasing the school leaving age in Britain had no ripple effects and that only the individuals directly affected by the reform increased their educational attainment. The reform thus only impinged on individuals with low education.

The Raising of the School Leaving Age (RoSLA) has been previously used, notably by Harmon and Walker (1995), to identify the financial returns to education in Great Britain. They estimate that the reform had a large impact on educational attainment and increased subsequent earnings of treated individuals by $15 \%$. However, one may be concerned that simply comparing cohorts born pre- and post-reform also captures time trends. This is especially a concern for these cohorts which were affected by the Second World War but also by the multiple post-war reforms, and a general improvement in the provision of health ${ }^{11}$.

As mentioned earlier, the reform reduced the cost of schooling and should thus have had a larger impact on the most financially constrained pupils. We thus posit that the effect of the 1944 Education Act on educational attainment is larger for pupils from a lower social background. Pre-reform, children from better background were more likely to remain in education past the age of 14 than their poorer peers, hence they are less affected by RoSLA than children from lower background. To capture this variation, the RoSLA dummy is interacted with the socio-economic group of the maternal grandfather. Pre-reform individuals from an unskilled manual background had almost three years less education than those born in a professional family. The reform reduced this gap, as it was designed, with the children from

\footnotetext{
${ }^{10}$ The reform has a substantial impact on the average education of the population. This compares with the college supply instrument used in Currie and Moretti (2003) which increases the average educational attainment by 0.08 year.

${ }^{11}$ Being of school age during the second world war is not a valid instrument as the war affected education but also potentially nutrition, which during puberty could affect the capacity of future mothers to have healthy children.
} 
the lower two social classes gaining almost a full year of education while children from the top three social classes see no significant change in their attainment (see Figure 2). The poorer individuals are directly affected by RoSLA whilst richer ones do not modify their behaviour. This creates identification power independently of time-trend. Note also, that $80 \%$ of the sample is born in a 8-year window around the reform and that the reform affected more than $65 \%$ of the individuals at risk (Table 1), so that the effect identified by the reform is for a large group of the population.

\section{Data}

The analysis is based on the 1958 National Child Development Study (NCDS) as in Lindeboom et al (2006). This is a longitudinal study of the universe of babies born in Great Britain between $3^{\text {rd }}$ and $9^{\text {th }}$ of March 1958. The 1958 original survey (Perinatal Mortality Survey) has been followed by 6 subsequent waves (NCDS 1-6). The PMS includes the mother's medical record as well as survey information. Birth weight is extracted from the medical record and is thus accurately measured ${ }^{12}$. While the attention is restricted to the PMS, some variables of interest, like maternal education, are only measured in later waves ${ }^{13}$. Mothers born outside of Great Britain were excluded as we do not know when they entered Britain or where they were educated. Also excluded are individuals reporting leaving school at a lower age than the minimum school leaving age. Including them in the sample (regardless of whether or not they are recoded) does not change the overall picture generated by the results. Only mothers aged 18 and above are included so that we do not impute to low level of schooling effects that stems from teenage motherhood. We exclude mothers older than 38 as

\footnotetext{
${ }^{12}$ We keep only life birth, singleton and exclude one observation with a recorded birth weight greater than $12 \mathrm{~kg}$, so valid observations range from 1,020 to 5,780. See details of selection in Annex 1.

${ }^{13}$ Maternal education is thus measured with error if mothers gained education after giving birth. This error would bias the OLS estimate towards zero. The delay before observing maternal education potentially creates some selection bias if children with low birth weight die before the wave at which maternal education should have been observed. Since infant mortality is low this bias is unlikely to be substantial. In Annex 1, we report no difference in the birth weight of babies by status of maternal education. So whether the child remains in the sample is independent of her birth weight.
} 
these babies would have been more at risk of complications during gestation which creates additional selection problems. These restrictions imposes that we only focus on mothers born between 1921 and 1940 which leads to a sample were one third of mothers faced a school leaving age of 15 .

Pregnancy resolution and the use of live births create selection issues. The econometrician only observes the birth weight for surviving foetuses but not for those who died from miscarriage or whose mother choose to terminate the pregnancy; this is a classic example of a sample selection problem. Liu (1998) finds negative foetal selection, where unobserved factors increasing the probability of giving birth tend to reduce birth weight whilst Rous et al. (2004) or Grossman and Joyce (1990) find positive foetal selection. The later also concludes that pregnancy resolution selection is less important than selection in prenatal care inputs. The data available to us only contains limited live births, which preclude any correction for selection ${ }^{14}$. However, since abortion was not legalised in Great Britain until 1967 (nine years after the NCDS cohort were born) the selection would solely be due to illegal abortion, miscarriage and stillbirth. It is difficult to find reliable, non-partisan estimates of the level of illegal abortions taking place prior to 1967. From the national statistics, around $10 \%$ of pregnancies end in miscarriage. Regan (2001) report that $50 \%$ of all miscarriages are due to random foetal mis-formation and that the majority of non random miscarriages are due to health conditions of the mother that are independent of her behaviour during pregnancy. Moreover, treatment during pregnancy to improve the health of foetuses at risk would also have been limited. Therefore the magnitude of selection and its possible effects on the estimates presented here are unknown but are likely to be relative small.

\footnotetext{
14 The data includes still birth however since no information on maternal education is available for these observations we cannot explore the issue of selection further.
} 
Birth weight is dependent on birth order and Currie and Moretti (2003) restrict their sample to first time mothers. First born children are about $125 \mathrm{~g}$ lighter than subsequent children but no significant different in birth weight is observed for later born children (see Figure 3). Since all mothers are observed giving birth in the same week focusing on first-born children creates additional selection problem. Older mothers are disproportionally less likely to be giving birth to their first child. Only $10 \%$ of mothers born in 1920 are giving birth for the first time in 1958, whilst this proportion is above $90 \%$ for mothers born in 1938. Being younger, first time mothers are also more educated. Hence, we keep all mothers and simply control for birth order to account for weight differential by parity and possible experience gained from previous pregnancies.

Finally, birth weight is reported in metric or imperial measures. Imperial measures create some bunching of the data. This bunching affects the definition of low birth weight since $3.5 \%$ of the data has a weight between 2,500 and 2,600 grams. We thus assess the sensitivity of the results to the measure of low birth weight ${ }^{15}$.

\section{Results}

Graphs of maternal education levels against average birth weight (Figures 4A) and probability of low birth weight (Figure 4B) reveal that, on average, educated mothers have heavier babies. Surprisingly mothers who exited at age 17 have the lightest babies. We do check that these mothers did not leave education because of their current pregnancy but find no evidence that this is the case. The outcomes for these mothers are all the more surprising considering that their observed inputs are rather favourable (Table 2). This group is small (98 observations) and results excluding it are not significantly different. From Table 2, we can see that the unconditional differences in birth weight between the least and most educated groups

\footnotetext{
${ }^{15}$ When not specified, low birth weight defines babies born at less than 2,500 grams.
} 
reaches 140 grams and that the most educated are almost $30 \%$ less likely to give birth to a low weight baby. However for the intermediate groups we do not find significant positive effect of education. These unconditional means hide the fact that for the least educated mothers, the observed births are for children higher up the birth order. The support for the hypothesis that maternal education reduces the risk of low birth weight is limited in the raw statistics.

Generally more educated mothers have more favourable outcomes. However, it is important to note that the difference in age and parity between mothers from the various education groups could affect these raw summary statistics. For example, mothers who have left school at 14 are more than 6 years older when they gave birth in 1958 than those who left school at 15 and have had an extra child. Also, the interval between this pregnancy and the previous one is less likely to be less than 2 years for the least educated group. A large discrepancy is observed for the decision to give birth at home. Almost $45 \%$ of the least educated mothers gave birth at home but only $25 \%$ of university educated mothers did so. The location of delivery may reflect some unobservable preferences of the mothers that would have affected her pregnancy. More educated mothers are in better health, as measured by their haemoglobin level and smoking behaviour, but not by their blood pressure. As expected access to care is similar between education groups but more educated mothers are more likely to have initiated care on time, maybe because they realised they were pregnant earlier. This may also indicate her willingness to invest in this pregnancy. Mothers who left school at 16 and 21 have had 1 to 2 extra days of gestation and the latter group is 7 percentage points less likely to have experienced abnormal pregnancy.

Education is also associated with differences in the family environment. Despite being younger, more educated mothers are less likely to be single at the time of birth. Conforming to assortative mating we observe a positive association between maternal 
education and her husband's education, social class and probability of working, so much so that more educated mothers can be thought of living in households with greater financial resources. Moreover, more educated mothers are significantly more likely to have been working during pregnancy. This has an ambiguous effect on birth weight since the income effect may be compensated by increased stress. Mothers leaving school at 15 are 10 percentage points more likely to have married their husband less than 9 months before giving birth for the first time (this defined a shot-gun wedding) than mothers who left school at 14 . However, this difference could be due to the variation in age between the two groups since for other educational groups no consistent relationship between education and the probability of shotgun wedding is found.

In Table 3, we report OLS estimates for various reduced form models. The outcome of interest is the birth weight of the child (additional birth outcomes and prenatal behaviours are reported thereafter). In the first column, we adopt a parsimonious specification which includes the gender of the baby (boys weigh $130 \mathrm{~g}$ more than girls), the mother's social class when she was 16 (insignificant), and dummies for maternal year of birth, region of residence and parity. The marginal effect of another year of maternal schooling is to increase the birth weight of her child by $13 \mathrm{~g}$ or less than $0.5 \%$. This is statistically significant but economically and medically irrelevant.

In columns 2, $3 \& 4$ additional - potentially endogenous - controls are added but without changing the significance or magnitude of the estimate. Model 2 adds an important determinant of birth weight: the gestation period. Each additional day of gestation increases birth weight by $17 \mathrm{~g}$. Gestation period and maternal education are mostly orthogonal to each other since the education estimate only falls slightly to $11 \mathrm{~g}$. Model three adds the mother's pre- 
pregnancy body mass index (BMI) as an indicator of maternal health ${ }^{16}$. Maternal BMI has a non-linear effect on the child birth weight with the heaviest babies being born from overweight but not obese mothers. Model 4 includes a set of indicators for the mother's smoking intensity prior to pregnancy. These indicators have the expected impact on birth weight, with more smoking being associated with lower birth weight. Smoking and BMI depends on choices made during but also post education and are thus potentially endogenous to the education decision. The evidence that the gestation period is a function of maternal education is more limited, hence our favoured specification is the one reported in model 2 which is used throughout the rest of the paper unless otherwise stated. It is also important to note that the grand-father's social class is not associated with significant variation in birth weight, so that the interaction between grand-father social class and RoSLA can be considered as instruments.

As discussed above, the relation between maternal education and birth weight is potentially biased by the endogeneity of education. The identification hinges on individuals from lower social background being directly affected by school reform while the remaining of the cohort is not. The results for the first stage estimations are presented in Appendix 2. Prereform, individuals from the bottom three social classes have on average 3.5 years less education than those from social class I. The penalty for those from social class II and III nonmanual ranges from 2 to 2.5 years. RoSLA has no significant effect on the educational attainment of children from the top social class but increases the average attainment of children originating from other social classes by up to 1.5 years.

The second stages are presented in Table 4. In the first panel, the dependent variable is the birth weight, measured in grams whilst in panel B and C, the probability of observing a

\footnotetext{
${ }^{16}$ Whilst maternal height is reported continuously, maternal weight is only reported in 10 categories, each category representing a $6 \mathrm{~kg}$ interval. We use the mid- point of the each category to approximate the bmi. As the effect of bmi on birth weight is likely to be non-linear we created dummies for under-weight, over-weight and obese.
} 
low birth weight baby is estimated for two alternative definitions. Each column reports results for models using the same specification as the one presented in Table 3, so moving from the most to the least parsimonious model. For each model, the instruments are found to be valid: a F-test of their significance is always greater than the critical value recommended by Bound et al. (1993) and the test of over-identification is always rejected. The exogeneity of maternal education is rejected in all models. As in most of the literature on the effect of education on health, and as in Currie and Moretti (2003), we find that after accounting for the endogeneity of education, the estimated of maternal education on birth weight is much larger and now hovers around $75 \mathrm{~g}$ or a $2 \%$ increase on the mean birth weight. As a robustness check, we also estimate these models on a sample of first born children only. The point estimates for these models range from $70 \mathrm{~g}$ to $77 \mathrm{~g}$ and are statistically significant (at the $10 \%$ level only).

In the second panel of Table 4, we estimate the probability of giving birth to a low birth weight baby, which would be a typical policy target. The marginal effects are always nil. The IV estimates show that maternal education reduces the likelihood of low birth weight by 2 percentage points (or a $30 \%$ reduction in the probability of low birth weight); however these estimates are never statistically significant. The definition of low birth weight is a "medical" definition; we further tested the sensitivity of our results using an alternative definition of low birth weight. Also, as mentioned above, a large proportion of the population has a bithweight just above the medical cut-off which could be due to approximation when converting from imperial to metric. The estimates are quite sensitive to the threshold used and we find marginally significant effects of an additional year of maternal education in the IV model on the likelihood of weighting less than $2,600 \mathrm{~g}$.

The point estimates are larger than those found by Currie and Moretti (2003). Their identifying strategy is based on an educational reform affecting individuals at the higher end of 
the schooling distribution whilst here the affected population has rather low level of education. The difference between these two studies could indicate diminishing returns to education. Moreover, the periods of interest are rather different: a 30 years span from the Seventies to the Nineties in their case and a single week in the late Fifties here, and dramatic medical knowledge had been gained. Since the medical communication to the general public, particularly the negative effects of maternal smoking during pregnancy, has changed drastically over this period, it is perfectly possible that maternal education had less of a role to play in the Fifties. Finally, the UK health system was mainly homogenous which would limit the role that maternal education can play to improve health outcomes compared to a competitive health system like in the US.

We now assess the mechanisms by which education could affect birth weight. The effects of maternal education on a number of different outcomes are reported in Table 5 using both OLS and 2SLS. The outcomes relate to birth outcomes, prenatal behaviours and environmental factors. Maternal education has a limited impact on the observed factors. In models accounting for its endogeneity maternal education only improves the family characteristics. Evidence of assortative mating is compelling and more educated women marry husbands from higher social class and with more education ${ }^{17}$. The effect of maternal education on birth weight may thus originate from improved financial conditions. Surprisingly, more education reduces the probability of giving birth in hospital. The absence of any effect of maternal education on the utilisation of health services is consistent with an environment where health information was limited and the provision of health homogenous. These results are substantially different from those obtained by Currie and Moretti (2003) and reflect the differences in the environment faced by mothers in the two surveys.

\footnotetext{
${ }^{17}$ There is some concerns here that the change in school leaving age is not a valid instrument with regards to the husband education. In case of assortative mating the husband is likely to be of a similar social class and birth cohort and would thus have been directly affected by the instrument.
} 
In Table 6, we extend model 4 with the additional variables presented in Table 5. These variables are all potentially endogenous as they are not independent of maternal education, but we include them to test the robustness of the effect of maternal education. Their inclusion drastically reduces the OLS estimates so that it becomes insignificant. However, the 2SLS estimate is barely reduced, at 68 grams, but is only significant at the $10 \%$ confidence interval. It is not surprising that the inclusion of these variables does not significantly change our conclusion for the 2SLS model since we have previously shown that they are mostly independent of maternal education. Nonetheless it is informative to measure the correlations between these inputs and birth weight. The number of pre-natal visits and the number of gestation days have a positive effect on birth weight, as found in the rest of the literature. Babies whose mothers suffered from abnormal pregnancy are 30 grams lighter, and surprisingly those that were delivered at home are heavier. This could be due to selection effects when mothers whose pregnancies have been diagnosed as potentially risky are giving birth in hospital. The interval between birth impacts on birth weight in a non-linear fashion. Babies, who are born less than a year after their siblings, are the smallest and weight between $80 \mathrm{~g}$ and $170 \mathrm{~g}$ less than babies born after a longer interval. All in all, the association between pre-natal care and birth weight is moderate.

Maternal health, as measured by haemoglobin level and blood pressure has no substantial effect on birth weight. After controlling for pre-pregnancy smoking intensity, smoking while pregnant reduces birth weight by $160 \mathrm{~g}$. This is the largest risk factor in this model, but, for this cohort, maternal education has no significant effect on smoking behaviour, so it is not the source of the effect of education on birth weight. Finally, husband's employment, education and social class are all positively correlated with higher birth weight, probably reflecting greater income level. Since maternal education improves the husband 
characteristics these could be the channel by which maternal education improves birth weight. However combining our results from Table 5 and 6 , the cumulative effect of maternal education on husband's education and social class only leads to an $8 \mathrm{~g}$ improvement. If these variables proxy for income, the income effect on birth weight is likely to be small. To conclude, the effect of maternal education on birth weight is mostly direct.

\section{Further discussion of results}

In Table 7, we provide various robustness checks on the quality of the instruments. These confirm the validity of the instruments and highlight some important heterogeneity in the effect of maternal education on birth weight. First, to assess whether our instrument is just capturing some trends in education, we generate two fake reforms of education: one that would have affected children born after 1930 and the second one increasing the education of children born after 1938. The first reform does not pass the F-test rule on instrument validity while the second one has the wrong sign. Both fake reforms lead to insignificant effect of maternal education on birth weight. The absence of significance of alternative dates for the reform is an additional indication that the instrument does not solely capture common trends between educational attainment and birth weight.

The second set of robustness checks presented in Table 7 focuses on specific populations which we expect to have been affected differently by the reform. First, we limit the population to individuals born in a tighter window around the reform (1928-1938 only). The validity of the instrument in the first stage is stronger than in the full sample and the estimates increases by $25 \%$ to $88 \mathrm{~g}$. We then split the sample into two sub-populations along their social background. Previous evidence shows that the reform mostly changed the educational attainment of individuals from lower social background. This is confirmed here as the instruments are found to have limited explanatory power for the sub-population of individuals 
from better off background. For mothers originating from the bottom three social classes, an increase in maternal education by one year increases birth weight by almost $200 \mathrm{~g}$, or $6 \%$ of the average birth weight. These results are still valid when we restrict the population to individuals born in the 10 years around the reform and split them by social background. The heterogeneity in the effect of maternal education on birth weight is also large and we report that for the treated group, the estimate reaches $190 \mathrm{~g}$.

The final set of robustness check divides the population of individuals born in the window around the reform by their schooling achievement. We argued previously that the reform only affected individuals with low level of education and thus divide the population between mothers who left school at or before the age of 16 and mothers who invested more in their education. We confirm that the reform had no ripple effect since the instruments are invalid for the most educated population. For the less educated population, on the other hand, we find strong significance of the instrument in the first stage and estimates of maternal education reaching $220 \mathrm{~g}^{18}$. All the robustness checks are in line with the argument that the reforms affected individuals born in 1934 or after, from lower social background and with low educational attainment, and support the validity of our claim that RoSLA interacted with social class provides an identifying strategy to estimate the returns to maternal education on birth weight. Concentrating on the population at risk, there is also clear evidence that the returns to maternal education are heterogenous and can reach $220 \mathrm{~g}$ or more than $6 \%$ of the average birth weight. However, additional tests, not reported here, show that even focusing on the treated population, maternal education does not significantly reduce the probability of low birth weight.

\footnotetext{
${ }^{18}$ Estimates limiting the population to mothers who left school at 14 or 15 reach $300 \mathrm{~g}$. However we are concerned that for this selected population the reform is an absorbing state as all individuals born after 1933 will have the same level of education.
} 


\section{Conclusion:}

Birth weight has been identified as a predictor of child health and development. The costs of low birth weight are considerable and its effects can reach well into adulthood. Maternal education may affect infant health through its positive affects on maternal health, prenatal behaviours such as smoking, the use of prenatal care, or family characteristics.

Using OLS on a sample of mothers in Fifties Britain, maternal education has significant, but small (11 grams) effects on birth weight. These effects broadly remain after controlling for gestation, maternal BMI and pre-pregnancy smoking behaviour. Relaxing the assumption of exogeneity of maternal education, an additional year of maternal education is estimated to increase the average birth weight by 75 grams (or $2 \%$ ). The identification stems from a reform of the school leaving age which affected mothers from lower social background.

For these cohorts, health services were homogenous and there was only limited health information available so we do not find any evidence that education increases the use of health services nor improve the health of the mother. We find evidence of assortative mating but these effects are too small to explain a substantial part of the impact of education on birth weight. Since education has limited effect on pre-natal factors, their inclusions in the birth weight model do not alter the estimate of maternal education. The robustness checks all support the validity of the identification strategy and highlight that the returns to maternal education on birth weight is heterogenous, reaching 200-220g for the treated population.

The gains of increasing the birth weight are multiple and can be observed from infancy to adulthood. To calculate the benefit of a policy increasing birth weight, we focus on two of these benefits. In the United States, Joyce (1999) estimates the additional health costs when a baby to range between $\$ 6$ and $\$ 10$ per grams in 1990 or $£ 4$ to $£ 7$ in today's price. 
Hence a policy increasing maternal education by one year would lead to a direct benefit of between $£ 240$ and $£ 420$. To these short-run gains, we add gains from higher earnings. Black et al. (2007) estimate an elasticity of earnings on birth weight of 0.1. Our favoured estimates are that one year of maternal education increases birth weight by $75 \mathrm{~g}$ or roughly $2 \%$, which will translate into a wage increase of $0.2 \%$. The average gross earnings in 2005 was $£ 24,000$ (Social Trends, 36), which we assumed to be fixed from the age of 20 until 65. The present value (at age 0 ) of the wage increase would thus be a rather small $£ 570$. Adding the top estimate of the health cost of low birth weight, the total benefit of a policy increasing maternal education by one year would be $£ 1,000$ maximum per child. Assuming that each woman had two children (which is an under-estimate in 1958) the total benefit per treated child would be $£ 2,000^{19}$. This estimate has only considered two types of benefits and can be thus seen as an underestimate, for example it does not include the increased mortality of low birth weight children. For the population directly affected by the reform, the estimated impact could be three times larger (increasing birth weight by $200 \mathrm{~g}$ rather than 75 on average). Moreover, due to the information and technology available for this cohort, these estimates are likely to be a lower bound. Even in a developed country with public provision of health and at a time when information on behaviour during maternity was limited, returns to maternal education on birth weight can be found. These additional returns to education should be considered in the current debates to increase minimum school leaving age.

\footnotetext{
${ }^{19}$ Interacting maternal education and parity does not reveal any non-linearity in the effect of education on birth weight.
} 
Table 1: Distribution of pre and post reform maternal education

\begin{tabular}{ccc}
\hline Age mother left education & $\begin{array}{c}\text { Minimum School } \\
\text { Leaving } \\
\text { Age 14 }\end{array}$ & $\begin{array}{c}\text { Minimum School } \\
\text { Leaving } \\
\text { Age 15 }\end{array}$ \\
\hline 14 & 67.59 & - \\
15 & 10.97 & 78.35 \\
16 & 11.15 & 14.19 \\
17 & 4.41 & 3.93 \\
18 & 1.71 & 2.05 \\
19 or 20 & 1.48 & 0.61 \\
21 or above & 2.70 & 0.86 \\
observation & 5,489 & 2,776 \\
\hline
\end{tabular}


Table 2: Average outcomes by level of education

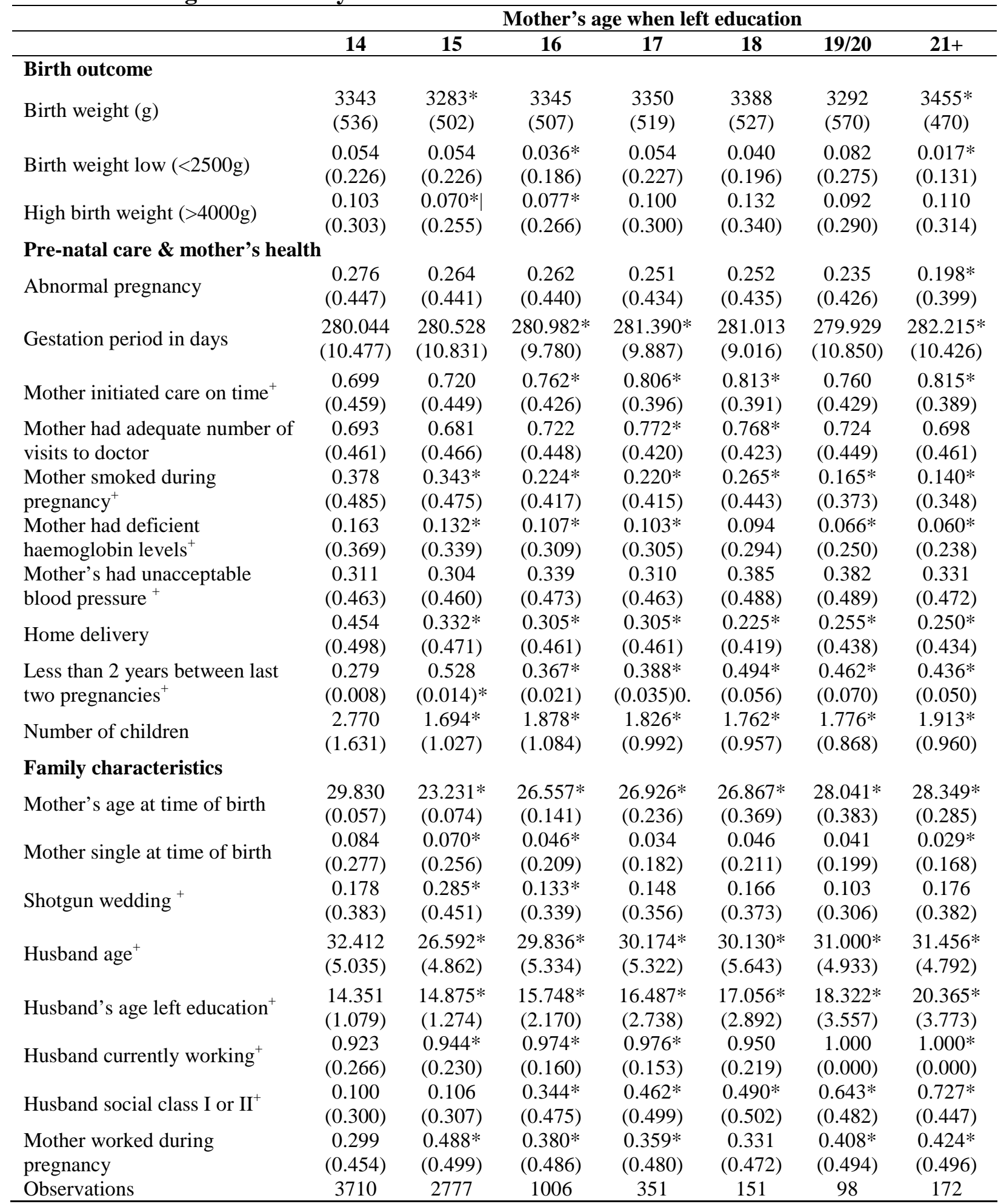

Note: *Significantly different than for the population of mothers who left school at 14.

${ }^{+}$Missing for some observations. The total number of observations are 8,260 for abnormal pregnancy, 8,071 for first visit during first trimester, 5,176 for haemoglobin level, 7,840 for blood pressure, 8,074 for shot-gun wedding, 8,072, 7,900, 7,727 and 7,377 for dad age, education, working and social class respectively. 
Table 3: Determinants of birth weight - OLS

\begin{tabular}{|c|c|c|c|c|}
\hline & $\begin{array}{l}\text { (1) } \\
\text { Base }\end{array}$ & $\begin{array}{c}\text { (2) } \\
\text { Gestation }\end{array}$ & $\begin{array}{c}\text { (3) } \\
\text { BMI }\end{array}$ & $\begin{array}{c}\text { (4) } \\
\text { Smoking }\end{array}$ \\
\hline Age mother left education: & $\begin{array}{l}13.36 \\
(3.31)\end{array}$ & $\begin{array}{l}10.98 \\
(2.88)\end{array}$ & $\begin{array}{l}12.52 \\
(3.28)\end{array}$ & $\begin{array}{c}9.88 \\
(2.59)\end{array}$ \\
\hline Male: & $\begin{array}{c}132.351 \\
(11.73)\end{array}$ & $\begin{array}{c}140.36 \\
(8.38)\end{array}$ & $\begin{array}{l}139.98 \\
(13.31)\end{array}$ & $\begin{array}{l}138.67 \\
(13.25)\end{array}$ \\
\hline Maternal grand dad - social class II & $\begin{array}{c}3.36 \\
(0.08)\end{array}$ & $\begin{array}{l}34.49 \\
(0.84)\end{array}$ & $\begin{array}{l}31.20 \\
(0.76)\end{array}$ & $\begin{array}{l}29.24 \\
(0.72)\end{array}$ \\
\hline Maternal grand dad - social class, Non Manual III & $\begin{array}{c}-16.78 \\
(0.37)\end{array}$ & $\begin{array}{l}14.15 \\
(0.32)\end{array}$ & $\begin{array}{l}13.13 \\
(0.30)\end{array}$ & $\begin{array}{l}15.38 \\
(0.35)\end{array}$ \\
\hline Maternal grand dad - Manual III & $\begin{array}{c}-10.98 \\
(0.27)\end{array}$ & $\begin{array}{l}17.44 \\
(0.44)\end{array}$ & $\begin{array}{l}16.51 \\
(0.41)\end{array}$ & $\begin{array}{l}18.50 \\
(0.46)\end{array}$ \\
\hline Maternal grand dad - social class IV & $\begin{array}{l}-29.38 \\
(0.69)\end{array}$ & $\begin{array}{l}-8.21 \\
(0.20)\end{array}$ & $\begin{array}{l}-9.22 \\
(0.22)\end{array}$ & $\begin{array}{l}-8.17 \\
(0.20)\end{array}$ \\
\hline Maternal grand dad - social class $\mathrm{V}$ & $\begin{array}{l}-40.08 \\
(0.93)\end{array}$ & $\begin{array}{l}-6.05 \\
(0.14)\end{array}$ & $\begin{array}{l}-7.48 \\
(0.18)\end{array}$ & $\begin{array}{l}-2.84 \\
(0.07)\end{array}$ \\
\hline Maternal grand dad - social class missing / no dad & $\begin{array}{l}-61.02 \\
(1.46)\end{array}$ & $\begin{array}{r}-32.30 \\
(0.78)\end{array}$ & $\begin{array}{r}-32.38 \\
(0.79)\end{array}$ & $\begin{array}{l}-29.61 \\
(0.72)\end{array}$ \\
\hline Mother underweight & & & $\begin{array}{l}-88.14 \\
(3.61)\end{array}$ & $\begin{array}{l}-74.98 \\
(3.06)\end{array}$ \\
\hline Mother overweight & & & $\begin{array}{l}84.90 \\
(6.05)\end{array}$ & $\begin{array}{l}82.45 \\
(5.91)\end{array}$ \\
\hline Mother obese & & & $\begin{array}{l}45.66 \\
(2.09)\end{array}$ & $\begin{array}{l}42.45 \\
(1.95)\end{array}$ \\
\hline Smoke 1-4 /day prior pregnancy & & & & $\begin{array}{l}-13.96 \\
(0.66)\end{array}$ \\
\hline Smoke 5-9/day prior pregnancy & & & & $\begin{array}{l}-84.66 \\
(5.58)\end{array}$ \\
\hline Smoke 10-14 /day prior pregnancy & & & & $\begin{array}{c}-103.56 \\
(6.47)\end{array}$ \\
\hline Smoke $15-19$ /day prior pregnancy & & & & $\begin{array}{c}-108.24 \\
(3.60)\end{array}$ \\
\hline Smoke $20-24$ /day prior pregnancy & & & & $\begin{array}{c}-162.90 \\
(4.51)\end{array}$ \\
\hline Smoke $25+/$ day prior pregnancy & & & & $\begin{array}{l}-99.97 \\
(1.21)\end{array}$ \\
\hline Days of gestation & & $\begin{array}{c}17.56 \\
(31.78)\end{array}$ & $\begin{array}{l}17.35 \\
(31.41)\end{array}$ & $\begin{array}{c}17.21 \\
(31.27)\end{array}$ \\
\hline Days of gestation missing & & $\begin{array}{l}26.23 \\
(1.31)\end{array}$ & $\begin{array}{l}24.73 \\
(1.43)\end{array}$ & $\begin{array}{l}26.99 \\
(1.56)\end{array}$ \\
\hline Constant & $\begin{array}{c}3038.60 \\
(33.80)\end{array}$ & $\begin{array}{c}-1896.06 \\
(10.71)\end{array}$ & $\begin{array}{c}-1873.96 \\
(10.61)\end{array}$ & $\begin{array}{c}-1761.24 \\
(10.00)\end{array}$ \\
\hline Dummies for year of mother's birth & Yes & Yes & Yes & Yes \\
\hline Dummies for region of residence & Yes & Yes & Yes & Yes \\
\hline Dummies for birth order & Yes & Yes & Yes & Yes \\
\hline $\mathrm{N}$ & \multicolumn{4}{|c|}{8265} \\
\hline $\mathrm{R} \mathrm{sq}$ & 0.040 & 0.164 & 0.170 & 0.178 \\
\hline
\end{tabular}

Note: Linear regression of birth weight in grams. Omitted categories are maternal grand dad social class I, mother born in 1921, the North West region, non smoker and first child born. Robust standard errors are used to compute the reported t-statistics in parentheses. 
Table 4: Maternal education effects on birth weight and low birth weight probability

\begin{tabular}{|c|c|c|c|c|}
\hline & $\begin{array}{l}\text { (1) } \\
\text { base }\end{array}$ & $\begin{array}{c}(2) \\
\text { gestation }\end{array}$ & $\begin{array}{c}(3) \\
\text { BMI }\end{array}$ & $\begin{array}{c}\text { (4) } \\
\text { Smoking }\end{array}$ \\
\hline \multicolumn{5}{|l|}{ Panel A: Birth weight } \\
\hline \multicolumn{5}{|l|}{ Age mother left education: } \\
\hline OLS & $\begin{array}{l}13.36 \\
(3.31)\end{array}$ & $\begin{array}{l}10.98 \\
(2.88)\end{array}$ & $\begin{array}{l}12.52 \\
(3.28)\end{array}$ & $\begin{array}{l}9.88 \\
(2.59)\end{array}$ \\
\hline IV & $\begin{array}{l}66.94 \\
(1.82)\end{array}$ & $\begin{array}{l}73.15 \\
(2.04)\end{array}$ & $\begin{array}{l}73.97 \\
(2.05)\end{array}$ & $\begin{array}{l}74.09 \\
(2.05)\end{array}$ \\
\hline \multicolumn{5}{|l|}{ F test of significance of instruments } \\
\hline $\mathrm{F}(7,8217)$ & 17.64 & 17.51 & 17.59 & 17.82 \\
\hline Partial $\mathrm{R}^{2}$ & 0.015 & 0.015 & 0.015 & 0.015 \\
\hline \multirow[t]{2}{*}{ Test of exogeneity: } & 2.78 & 4.24 & 4.11 & 4.52 \\
\hline & 0.09 & 0.04 & 0.04 & 0.03 \\
\hline Test of overidentification: $\chi^{2}(6)$ & 4.54 & 3.13 & 3.33 & 3.07 \\
\hline $\mathrm{p}$ & 0.60 & 0.79 & 0.77 & 0.80 \\
\hline \multicolumn{5}{|l|}{ Panel B: Low birth weight } \\
\hline Probit marginal effects & $\begin{array}{l}-0.002 \\
(1.33)\end{array}$ & $\begin{array}{l}-0.002 \\
(1.05)\end{array}$ & $\begin{array}{l}-0.001 \\
(1.07)\end{array}$ & $\begin{array}{l}-0.001 \\
(0.79)\end{array}$ \\
\hline Instrumental variable & $\begin{array}{l}-0.023 \\
(1.44)\end{array}$ & $\begin{array}{l}-0.017 \\
(1.26)\end{array}$ & $\begin{array}{l}-0.018 \\
(1.30)\end{array}$ & $\begin{array}{l}-0.018 \\
(1.33)\end{array}$ \\
\hline \multirow[t]{3}{*}{ Test of exogeneity: } & 1.19 & 1.96 & 1.93 & 2.02 \\
\hline & 0.27 & 0.16 & 0.16 & 0.15 \\
\hline & 6.43 & 5.39 & 5.30 & 5.62 \\
\hline $\begin{array}{l}\text { Test of overidentification: } \chi^{2}(6) \\
\mathrm{p}\end{array}$ & 0.37 & 0.49 & 0.51 & 0.47 \\
\hline \multicolumn{5}{|l|}{$\begin{array}{l}\text { Panel C: Weight under } \mathbf{2 , 6 0 0} \mathbf{g} \\
\text { Age mother left education: }\end{array}$} \\
\hline Probit marginal effects & $\begin{array}{l}-0.004 \\
(1.60)\end{array}$ & $\begin{array}{l}-0.003 \\
(1.13)\end{array}$ & $\begin{array}{l}-0.002 \\
(1.13)\end{array}$ & $\begin{array}{r}-0.002 \\
(0.89)\end{array}$ \\
\hline Instrumental variable & $\begin{array}{l}-0.032 \\
(1.74)\end{array}$ & $\begin{array}{l}-0.031 \\
(1.76)\end{array}$ & $\begin{array}{l}-0.032 \\
(1.81)\end{array}$ & $\begin{array}{r}-0.032 \\
(1.83)\end{array}$ \\
\hline \multirow{3}{*}{ Test of exogeneity: $\quad \chi^{2}(1)$} & 2.54 & 3.17 & 3.31 & 3.56 \\
\hline & 0.11 & 0.07 & 0.07 & 0.06 \\
\hline & 3.31 & 3.34 & 3.33 & 3.38 \\
\hline $\mathrm{p}$ & 0.77 & 0.77 & 0.77 & 0.76 \\
\hline
\end{tabular}

Note: Robust t-statistics reported in parentheses. Number of observations for all models: 8265 .

The models are based on the same specifications as those presented in Table 3. For the low birth weight model, a linear probability model was also estimated and led to similar results.

Instruments are: RoSLA and interactions with grand father social class. 
Table 5: Effect of maternal education on other outcomes

\begin{tabular}{|c|c|c|c|}
\hline Outcome & OLS & IV & Observations \\
\hline High birth weight $(>4000 \mathrm{~g})$ & $\begin{array}{l}0.002 \\
(1.06)\end{array}$ & $\begin{array}{l}0.021 \\
(1.10)\end{array}$ & 8265 \\
\hline Abnormal pregnancy & $\begin{array}{l}-0.005 \\
(1.46)\end{array}$ & $\begin{array}{l}-0.010 \\
(0.35)\end{array}$ & 8260 \\
\hline Mother initiated care on time & $\begin{array}{l}0.005 \\
(1.15)\end{array}$ & $\begin{array}{l}-0.013 \\
(0.47)\end{array}$ & 8071 \\
\hline $\begin{array}{l}\text { Mother had adequate number of visits to } \\
\text { doctor }\end{array}$ & $\begin{array}{l}0.001 \\
(0.26)\end{array}$ & $\begin{array}{l}0.011 \\
(0.36)\end{array}$ & 8265 \\
\hline Mother smoked during pregnancy ${ }^{\mathrm{A}}$ & $\begin{array}{r}-0.010 \\
(2.87)\end{array}$ & $\begin{array}{l}0.006 \\
(0.36)\end{array}$ & 8184 \\
\hline Mother gave birth at home & $\begin{array}{l}-0.021 \\
(4.62)\end{array}$ & $\begin{array}{l}0.76 \\
(2.04)\end{array}$ & 8265 \\
\hline Less than 2 years between pregnancies & $\begin{array}{l}0.028 \\
(5.29)\end{array}$ & $\begin{array}{l}0.072 \\
(1.74)\end{array}$ & 5110 \\
\hline Mother had deficient haemoglobin levels & $\begin{array}{l}-0.013 \\
(3.24)\end{array}$ & $\begin{array}{l}-0.011 \\
(0.40)\end{array}$ & 5176 \\
\hline Mother's had acceptable blood pressure & $\begin{array}{l}-0.005 \\
(1.14)\end{array}$ & $\begin{array}{l}0.003 \\
(0.11)\end{array}$ & 7840 \\
\hline Mother single at time of birth & $\begin{array}{l}-0.003 \\
(1.59)\end{array}$ & $\begin{array}{l}-0.008 \\
(0.52)\end{array}$ & 8265 \\
\hline Shotgun wedding & $\begin{array}{l}0.001 \\
(0.37)\end{array}$ & $\begin{array}{l}-0.033 \\
(1.31)\end{array}$ & 8074 \\
\hline Husband age & $\begin{array}{l}0.071 \\
(2.22)\end{array}$ & $\begin{array}{l}-0.238 \\
(1.03)\end{array}$ & 7473 \\
\hline Husband years of education & $\begin{array}{l}0.657 \\
(24.30)\end{array}$ & $\begin{array}{l}0.600 \\
(5.70)\end{array}$ & 7210 \\
\hline Husband currently working & $\begin{array}{l}0.007 \\
(3.68)\end{array}$ & $\begin{array}{l}-0.015 \\
(1.06)\end{array}$ & 7058 \\
\hline Husband social class I or II & $\begin{array}{c}0.058 \\
(17.99)\end{array}$ & $\begin{array}{l}0.074 \\
(3.26)\end{array}$ & 7377 \\
\hline Mothers worked during pregnancy & $\begin{array}{r}-0.001 \\
(0.18)\end{array}$ & $\begin{array}{l}-0.033 \\
(0.93)\end{array}$ & 8265 \\
\hline
\end{tabular}

Note: The specification used for all models is identical to the one reported for model 2 in Table 3. Robust tstatistics reported in parentheses.

A this specification controls for smoking behaviour prior pregnancy.

Instruments are: RoSLA and interactions with grand father social class 
Table 6: Effects of prenatal inputs and maternal education on birth weight

\begin{tabular}{|c|c|c|}
\hline & OLS & IV \\
\hline Age mother left education: & $\begin{array}{l}3.331 \\
(0.78)\end{array}$ & $\begin{array}{c}66.020 \\
(1.83)\end{array}$ \\
\hline \multicolumn{3}{|l|}{ Pre-natal care } \\
\hline Mother initiated care on time & $\begin{array}{l}0.478 \\
(0.04)\end{array}$ & $\begin{array}{l}0.534 \\
(0.04)\end{array}$ \\
\hline Mother had adequate number of visits to doctor & $\begin{array}{c}63.584 \\
(5.14)\end{array}$ & $\begin{array}{c}63.586 \\
(5.14)\end{array}$ \\
\hline Mother had abnormal pregnancy & $\begin{array}{c}-26.868 \\
(2.27)\end{array}$ & $\begin{array}{c}-26.962 \\
(2.28)\end{array}$ \\
\hline Mother had deficient haemoglobin levels & $\begin{array}{l}5.140 \\
(0.24)\end{array}$ & $\begin{array}{l}4.479 \\
(0.21)\end{array}$ \\
\hline Mother's had acceptable blood pressure & $\begin{array}{c}19.074 \\
(1.59)\end{array}$ & $\begin{array}{l}19.023 \\
(1.59)\end{array}$ \\
\hline Days of gestation & $\begin{array}{l}16.322 \\
(29.28)\end{array}$ & $\begin{array}{c}16.334 \\
(29.34)\end{array}$ \\
\hline Interval between birth $>1$ but $<2$ years & $\begin{array}{c}82.447 \\
(2.22)\end{array}$ & $\begin{array}{c}81.984 \\
(2.20)\end{array}$ \\
\hline Interval between birth $>2$ but $<3$ years & $\begin{array}{c}127.842 \\
(3.36)\end{array}$ & $\begin{array}{c}127.817 \\
(3.35)\end{array}$ \\
\hline Interval between birth $>3$ but $<4$ years & $\begin{array}{c}115.518 \\
(2.90)\end{array}$ & $\begin{array}{c}115.756 \\
(2.90)\end{array}$ \\
\hline Interval between birth $>4$ but $<5$ years & $\begin{array}{c}171.862 \\
(4.06)\end{array}$ & $\begin{array}{c}171.411 \\
(4.04)\end{array}$ \\
\hline Interval between birth $>5$ but $<6$ years & $\begin{array}{c}102.104 \\
(2.50)\end{array}$ & $\begin{array}{c}103.115 \\
(2.52)\end{array}$ \\
\hline Interval between birth $>6$ & $\begin{array}{l}2.138 \\
(0.03)\end{array}$ & $\begin{array}{l}3.064 \\
(0.05)\end{array}$ \\
\hline Previous birth was miscarriage & $\begin{array}{c}178.792 \\
(1.45)\end{array}$ & $\begin{array}{c}178.095 \\
(1.46)\end{array}$ \\
\hline Delivery at home & $\begin{array}{c}61.344 \\
(4.14)\end{array}$ & $\begin{array}{c}60.165 \\
(4.06)\end{array}$ \\
\hline Smoked during pregnancy & $\begin{array}{c}-159.081 \\
(7.93)\end{array}$ & $\begin{array}{c}-159.534 \\
(7.94)\end{array}$ \\
\hline Husband characteristics & & \\
\hline Single & $\begin{array}{c}-31.932 \\
(0.80)\end{array}$ & $\begin{array}{c}-31.461 \\
(0.79)\end{array}$ \\
\hline Shotgun wedding & $\begin{array}{c}-2.436 \\
(0.17)\end{array}$ & $\begin{array}{r}-1.785 \\
(0.12)\end{array}$ \\
\hline Husband currently working & $\begin{array}{c}92.714 \\
(3.41)\end{array}$ & $\begin{array}{c}93.803 \\
(3.46)\end{array}$ \\
\hline Husband age & $\begin{array}{l}0.799 \\
(0.54)\end{array}$ & $\begin{array}{l}0.858 \\
(0.58)\end{array}$ \\
\hline Husband years of education & $\begin{array}{l}8.050 \\
(2.33)\end{array}$ & $\begin{array}{l}8.832 \\
(2.75)\end{array}$ \\
\hline Husband - social class I or II & $\begin{array}{c}32.594 \\
(1.99)\end{array}$ & $\begin{array}{c}33.676 \\
(2.07)\end{array}$ \\
\hline Mother worked during pregnancy & $\begin{array}{l}2.932 \\
(0.22)\end{array}$ & $\begin{array}{l}3.101 \\
(0.23)\end{array}$ \\
\hline Constant & $\begin{array}{c}-1,876.050 \\
(8.55)\end{array}$ & $\begin{array}{c}-2,991.263 \\
(4.51)\end{array}$ \\
\hline Dummies for year of mother's birth & Yes & Yes \\
\hline Dummies for region of residence & Yes & Yes \\
\hline Dummies for birth order & Yes & Yes \\
\hline Observation & 8260 & 8260 \\
\hline R-squared & 0.19 & 0.19 \\
\hline
\end{tabular}

Note: Robust t-statistics in parentheses. Specification identical to model 4 plus additional dummies for missing values for pre-natal visits, haemoglobin deficiency, blood pressure, location of delivery, period between pregnancy, single, husband currently working, husband's age, husband's years of education and husband's social class. 
Table 7: Robustness check: Estimate of maternal education on birth weight (in grams)

\begin{tabular}{|c|c|c|c|}
\hline Population: & OLS & IV. & obs \\
\hline $\begin{array}{l}\text { Fake reform increasing } \\
\text { education for mother born } \\
\text { in } 1930\end{array}$ & $\begin{array}{l}10.98 \\
(2.88)\end{array}$ & $\begin{array}{l}62.04 \\
(0.94)\end{array}$ & 8265 \\
\hline F- first stage & & 6.31 & \\
\hline $\begin{array}{l}\text { Fake reform increasing } \\
\text { education for mother born } \\
\text { in } 1938\end{array}$ & $\begin{array}{l}10.98 \\
(2.88)\end{array}$ & $\begin{array}{l}3.236 \\
(0.03)\end{array}$ & 8265 \\
\hline F- first stage & & 11.52 & \\
\hline Born $1928-38$ only & $\begin{array}{c}14.552 \\
(3.19)\end{array}$ & $\begin{array}{l}88.118 \\
(2.63) \\
17.07\end{array}$ & 5880 \\
\hline $\begin{array}{l}\text { Dad occ III non manual and } \\
\text { higher } \\
\text { F- first stage }\end{array}$ & $\begin{array}{l}10.589 \\
(5.616)\end{array}$ & $\begin{array}{c}77.761 \\
(1.02) \\
4.96\end{array}$ & 1620 \\
\hline $\begin{array}{l}\text { Dad occ III manual and } \\
\text { lower } \\
\text { F- first stage }\end{array}$ & $\begin{array}{c}12.276 \\
(2.33)\end{array}$ & $\begin{array}{c}192.747 \\
(2.77) \\
18.10\end{array}$ & 6645 \\
\hline $\begin{array}{l}\text { Born } 1928-38 \text {, dad occ III } \\
\text { non manual and higher } \\
\text { F- first stage }\end{array}$ & $\begin{array}{c}15.939 \\
(2.41)\end{array}$ & $\begin{array}{c}111.71 \\
(1.29) \\
3.19\end{array}$ & 1141 \\
\hline $\begin{array}{l}\text { Born } 1928-38 \text {, dad occ III } \\
\text { manual and lower } \\
\text { F- first stage }\end{array}$ & $\begin{array}{c}13.636 \\
(2.14)\end{array}$ & $\begin{array}{l}191.376 \\
(2.96) \\
19.37\end{array}$ & 4741 \\
\hline $\begin{array}{l}\text { Born } 1928-38 \text { and left } \\
\text { school at or before age } 16 \\
\text { F- first stage }\end{array}$ & $\begin{array}{c}20.760 \\
(1.80)\end{array}$ & $\begin{array}{c}222.322 \\
(2.87) \\
22.08\end{array}$ & 5300 \\
\hline $\begin{array}{l}\text { Born } 1928-38 \text { and left } \\
\text { school at } 17 \text { or later } \\
\text { F- first stage }\end{array}$ & $\begin{array}{l}17.31 \\
(1.64)\end{array}$ & $\begin{array}{c}3.090 \\
(0.05) \\
3.22\end{array}$ & 582 \\
\hline
\end{tabular}

Note: Estimates based on model (2) specification. Robust t-statistics reported in parentheses. Instruments are: RoSLA and interactions with grand father social class. 
Figure 1: Average age mother left education by year of birth.

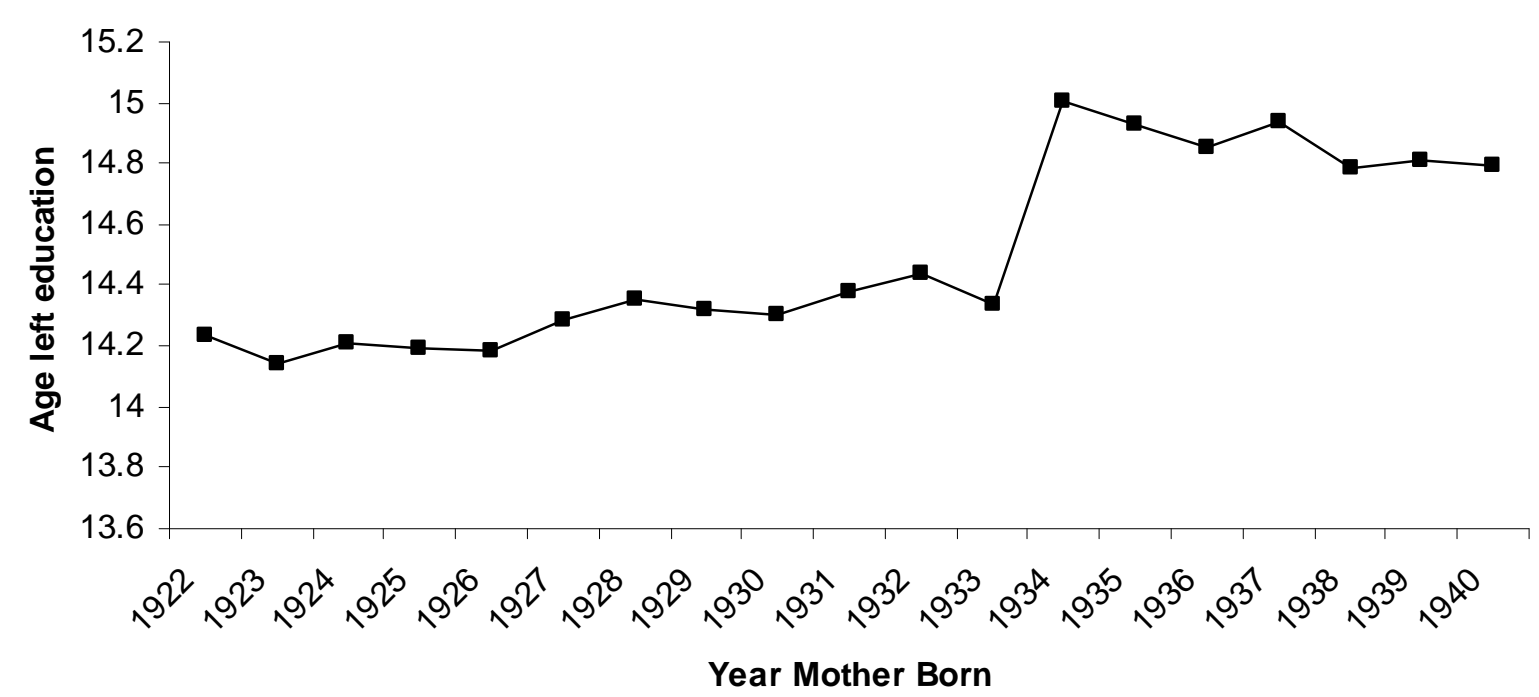

Note: Estimated coefficient from dummy variables on year born on years of education, including controls for region.

Figure 2: Effect of change in school leaving age by social class.

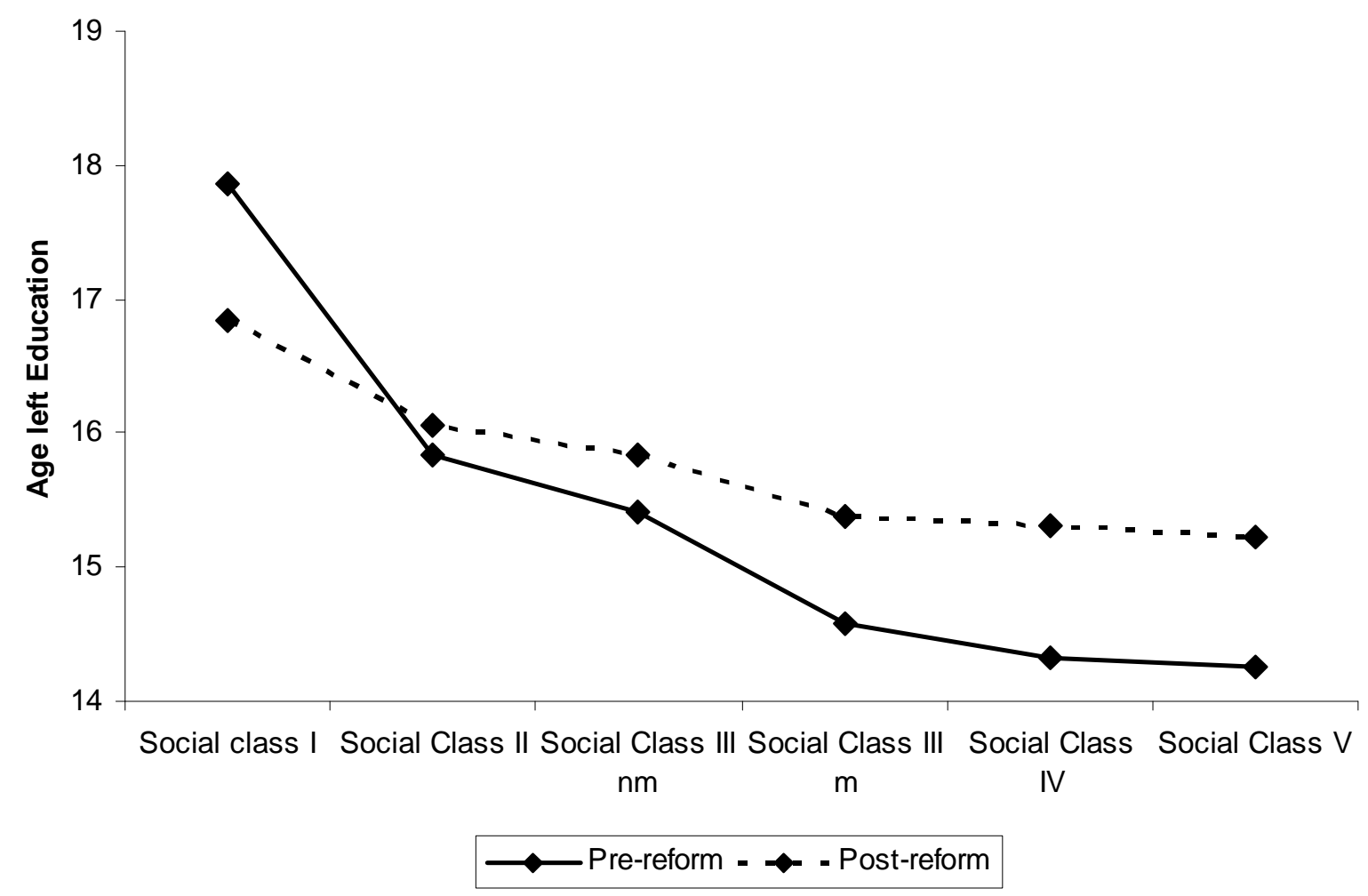


Figure 3: Birth order and birth weight

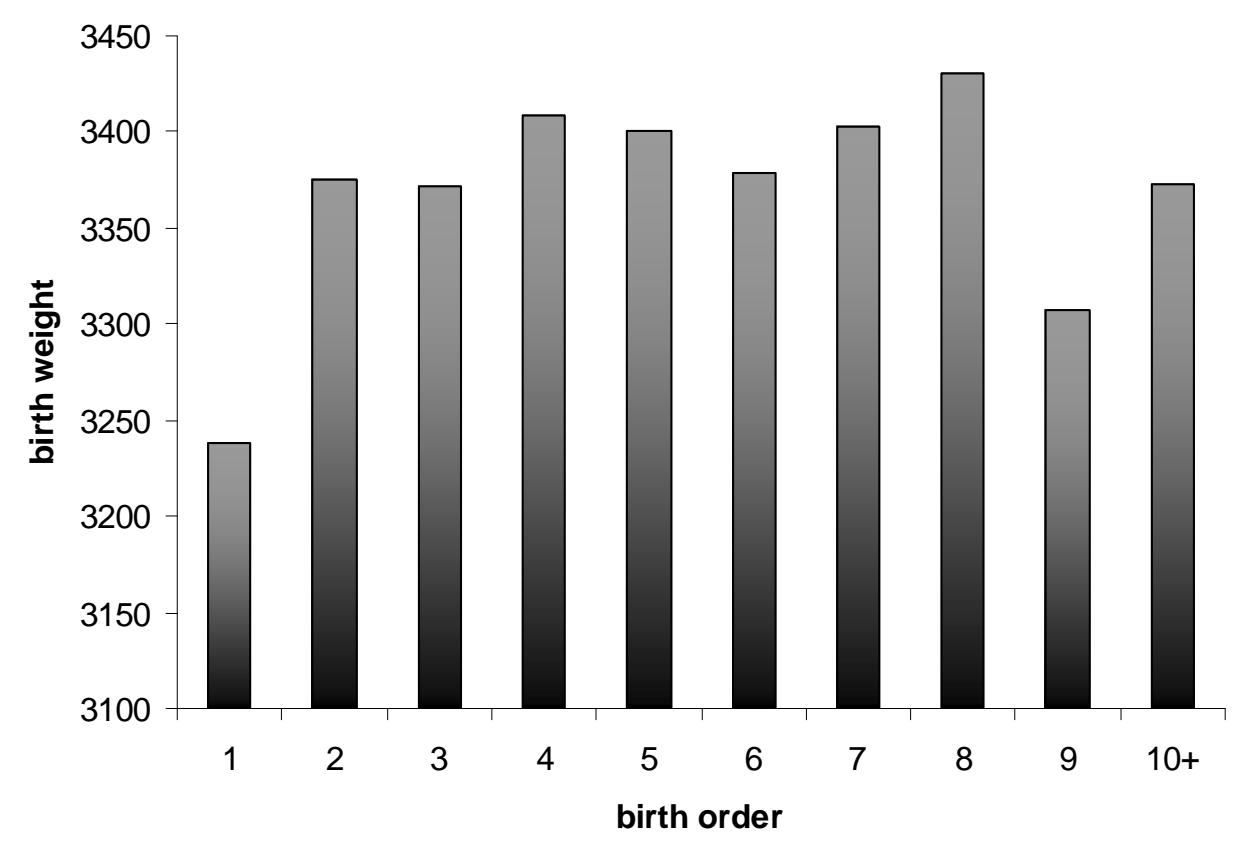


Figure 4A: Maternal education and birth weight (in grams)

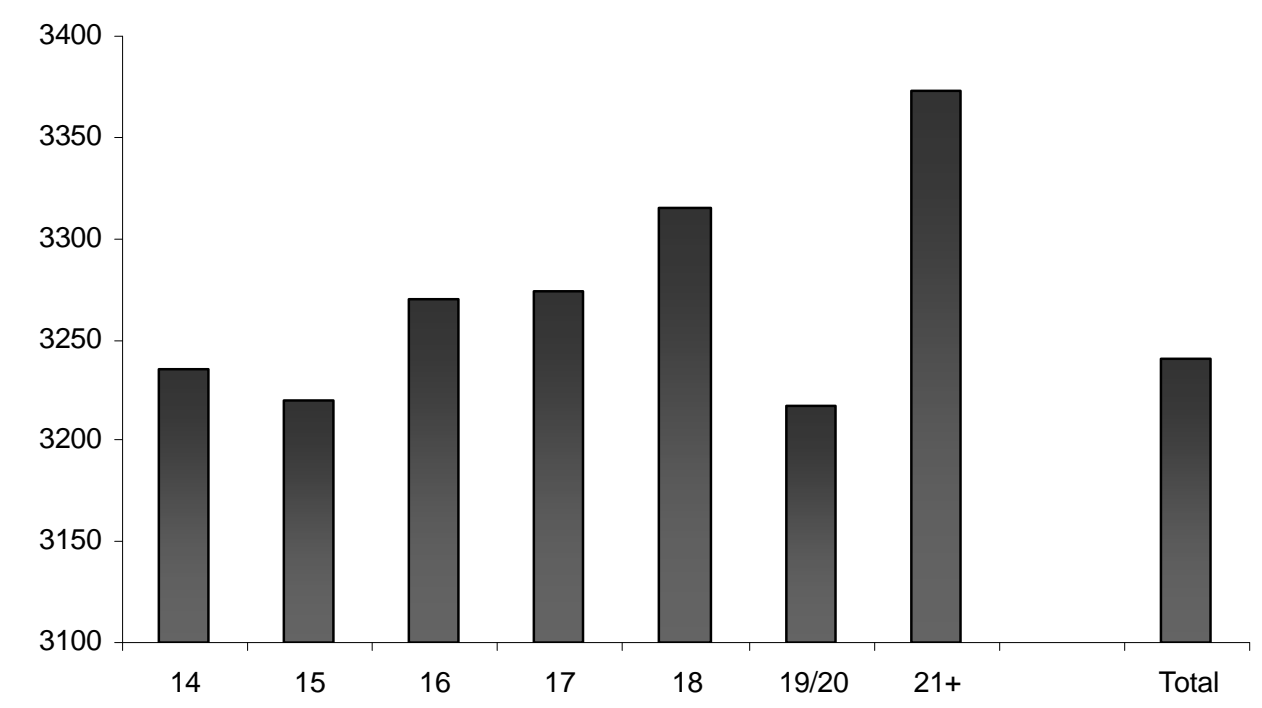

Note: Birth weight in grams adjusted for birth order. The adjustments are the estimated coefficients of a regression of birth weight on dummies for birth order.

Figure 4B: Maternal education and low birth weight probability $(<2,500$ grams $)$

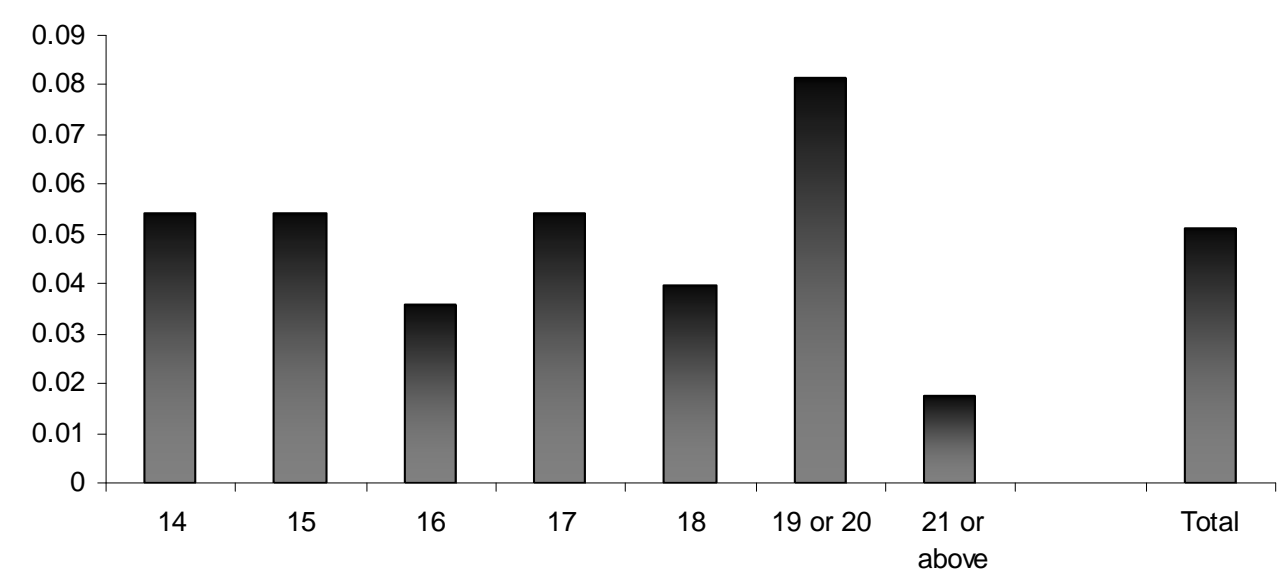




\section{References:}

Almond D., K. Chay and D. Lee (2005), "the costs of low birth weight", Quarterly Journal of Economics, 120, 1031-1083

Aylward, G. P., Pfeiffer, S. I., Wright, A. and A. J. Verhulst, (1989), "Outcome studies of low birth weight, infants published in the last decade: A meta-analysis", Journal of Pediatrics, 115, 515-520.

Becker, G.S. and C.B. Mulligan (1997), "The endogenous determination of time preferences", Quarterly Journal of Economics, August .

Behrman, J.R. and B. Wolfe (1989), "Does more schooling make women better nourished and healthier? Adult sibling random and fixed effects estimates for Nicaragua", Journal of Human Resources, 24, 644-663.

Black S., P. Devereux and K. Salvanes, (2007) "From the Cradle to the Grave: the effect of birth weight on adult outcomes", Quarterly Journal of Economics, 122, 409-439

Bound, J., Jaeger, D.A. and R. Baker (1993), "Problems with IV estimation when the correlation between instruments and the endogenous explanatory variable is weak", Journal of the American Statistical Society, 90, 430, 443-450.

Case A., A. Fertig and C. Paxson (2005), "The lasting impact of childhood health and circumstances", Journal of Health Economics, 24, 365-389

Chevalier, A., Harmon, C., Walker, I. and Zhu Y. (2004) "Does Education Raise Productivity, or Just Reflects It?”, Economic Journal, 114, F499-F517

Chevalier, A., Harmon, C., O' Sullivan, V. and Walker, I. (2005) "The Impact of Parental Income and Education on the Schooling of their Children”, IZA, 1496.

Corman H. and S. Chaikind (1998), "The effects of low birth weight on school performance and behaviour of school aged children", Economics of Education Review, 17: 307 316.

Currie, J. and R. Hyson, (1999), "Is the impact of health shocks cushioned by socioeconomic status? The case of birth weight", American Economic Review, 89, 245-250.

Currie, J and E. Moretti (2003). "Mother's education and the intergenerational transmission of human capital: Evidence from college openings", Quarterly Journal of Economics, 118 , no. $4,1495-1532$.

Currie, J. and E. Moretti (2005) "Biology as destiny? Short and long-run determinants of intergenerational transmission of birth weight", National Bureau of Economic Research, 11567

Desai, S. and S. Alva (1998), "Maternal education and child's health: Is there a strong causal relationship?", Demography, 35, 71-81.

Doyle O., C. Harmon and I. Walker (2005) "The impact of Parental Income and Education on the Health of their Children", IZA, 1832

Evans, W.N. and J.S. Ringel (1999). “Can higher cigarette taxes improve birth outcomes?”, Journal of Public Economics, 72, 135-154.

Fuchs, V.R. (1982). "Time preference and health: an exploratory study", in V.R. Fuchs (ed), Economic aspects of health. Chicago Illinois: University of Chicago Press. 
Galindo-Rueda, F. (2003), "The intergenerational effect of parental schooling: Evidence from the British 1947 school leaving age reform", Centre for Economic Performance, London School of Economics, mimeo.

Grossman, M. (1975), “The correlation between health and schooling”, in Nestor E. Terleckyj (ed.), Household Production and Consumption. New York: Columbia University Press for NBER.

Grossman, M (2006), "Education and non-market outcomes", Handbook of Economics of Education, Hanushek E. and F. Welsh (Eds), Elsevier, Holland

Grossman, M. and T. Joyce (1990), "Unobservables, pregnancy resolutions and birth weight production in New York City”, Journal of Political Economy, 98, 983-1007.

Harmon C. and I. Walker (1995), "Estimates of the economic return to schooling in the United Kingdom", American Economic Review, 85, 1278-1286.

Institute of Medicine (1985). Preventing low birth weight, Washington DC, National Academy Press.

Jones K. (2003) Education in Britain: 1944 to the present, Cambridge, Polity.

Joyce, T. (1994), "Self selection, prenatal care and birth weight among blacks whites and hispanics in New York City", Journal of Human Resources, 29, 762-794.

Joyce, T. (1999). "Impact of augmented prenatal care on birth outcomes of Medicaid recipients in New York City", Journal of Health Economics, 18, 31-67.

Kenkel D. (1991). Health behaviour, health knowledge and schooling, Journal of Political Economy, 99, 287-305

Lewitt, E.M., Baker, L.S., Corman, H. and P.H. Shionio (1995), "The direct costs of low birth weight", The Future of Children, 5, 35-51.

Lindeboom M., A. Llena-Nozal and B. van der Klaauw (2006) "Parental Education and Child Health: Evidence from a Schooling Reform”, IZA, 2516

Liu, (1998). "Birth outcomes and the effectiveness of prenatal care", Health Services Research, 32, 6, 805-822.

Lleras-Muney, A. (2005), "The relationship between education and adult mortality in the US", Review of Economic Studies, number 8986.

Lleras-Muney, A., and F. Lichtenberg (2006), "The effect of education on medical technology adoption: Are the more educated more likely to use new drugs?" Annales d'Economie et Statistique (forthcoming).

Michael, R.T. (1973), "Education in non-market production", Journal of Political Economy, 81(2), 306-327.

Munashinge, L., and N. Sicherman (2000), "Why do dancers smoke? Time preference, occupational choice and wage growth", NBER, 7542.

National Centre for Health Statistics (1993), Advanced Report of Final Natality Statistics, Hyattsville: MD public Health Service.

Regan L. (2001). "Misscarriage: what every woman needs to know”, Orion Book

Rosenzweig, M.R., and T.P. Shultz, (1983), "Estimating a household production function: heterogeneity, the demand for health inputs and their effect on birth weight", Journal of Political Economy, 91, 723-746. 
Rous, J.J., Jewell, R.T. and R.W. Brown (2004), “The effect of prenatal care on birth weight: A full information maximum likelihood approach", Health Economics, 13, 251-264.

Sexton, M. and J.R. Hebel (1984), "A clinical trial of change in maternal smoking and its effects on birth weight”, Journal of American Medical Association, 251, 7, 911-915.

Tinker A. and E. Rasom (2002) "Healthy mothers and healthy new borns: the vital link", Population Reference Bureau, http://www.prb.org/Publications/PolicyBriefs

Thomas, D., Strauss, J. and M.H. Henriques (1991), "How does mother's education affect child height?", Journal of Human Resources, 26, 1, 183-211.

Welch, F. (1970), “Education in production”, Journal of Political Economy, 78, 35-59.

Wilcox, A.J., (2001), "On the importance - and the unimportance - of birth weight", International Journal of Epidemiology, 30, 1233-1241.

Wilcox, A.J., and I.T. Russell, (1983), "Birth weight and perinatal mortality", International Journal of Epidemiology. 12, 314-318

World Bank (1993), World Development Report 1993: Investing in Health, New York: Oxford University Press 
Annex 1: Additional results

Table A1: Number of observations and mean characteristics at all selection stages

\begin{tabular}{llll}
\hline Selection criteria & Observations & $\begin{array}{l}\text { Birth weight } \\
\text { of remaining } \\
\text { population }\end{array}$ & $\begin{array}{l}\text { Maternal } \\
\text { education } \\
\text { (age left) }\end{array}$ \\
\hline \hline $\begin{array}{l}\text { Perinatal Mortality Survey } \\
\text { Live birth with positive birth weight }(<6 \mathrm{~kg})\end{array}$ & 18,558 & - & - \\
Maternal education missing (recoded in wave & 9,9635 & 3,312 & - \\
3 out of 11,691 respondents) & & 3,311 & 14.99 \\
Mother born in UK & 9,403 & 3,312 & 14.95 \\
Mother year of birth missing & 9,397 & 3,312 & 14.95 \\
Mother defier on school reform & & 3,315 & 15.00 \\
Mother aged less than 16 or older than 38 & 8,981 & 3,311 & 15.02 \\
Mother birth order missing & 8,500 & 3,311 & 15.02 \\
Twin birth & 8,433 & 3,325 & 15.02 \\
Note: a Mother claiming to have finished schooling at a lower age than minimum school leaving age.
\end{tabular}


Table A2: First stage results:

\begin{tabular}{|c|c|}
\hline & mother age left Education \\
\hline Maternal grand dad - social class II & $\begin{array}{l}-2.034 \\
(8.41)\end{array}$ \\
\hline Maternal grand dad - social class, Non & -2.442 \\
\hline Manual III & $(9.53)$ \\
\hline Maternal grand dad - social class Manual III & $\begin{array}{l}-3.250 \\
(14.24)\end{array}$ \\
\hline Maternal grand dad - social class IV & $\begin{array}{l}-3.483 \\
(15.19)\end{array}$ \\
\hline Maternal grand dad - social class V & $\begin{array}{l}-3.534 \\
(15.43)\end{array}$ \\
\hline $\begin{array}{l}\text { Maternal grand dad - social class missing / } \\
\text { no dad }\end{array}$ & $\begin{array}{l}-3.195 \\
(13.77)\end{array}$ \\
\hline Mother affected by RoSLA to 15 & $\begin{array}{l}-0.587 \\
(1.60)\end{array}$ \\
\hline Maternal grand dad - s.c. II * RoSLA15 & $\begin{array}{l}1.291 \\
(3.69)\end{array}$ \\
\hline $\begin{array}{l}\text { Maternal grand dad - s.c. NM III * } \\
\text { RoSLA15 }\end{array}$ & $\begin{array}{l}1.501 \\
(3.99)\end{array}$ \\
\hline Maternal grand dad - s.c. M III * RoSLA15 & $\begin{array}{l}1.852 \\
(5.63)\end{array}$ \\
\hline Maternal grand dad - s.c. IV * RoSLA15 & $\begin{array}{l}2.018 \\
(6.10)\end{array}$ \\
\hline Maternal grand dad - s.c. $\mathrm{V} *$ RoSLA15 & $\begin{array}{l}2.000 \\
(6.08)\end{array}$ \\
\hline $\begin{array}{l}\text { Maternal grand dad - social class missing / } \\
\text { no dad * RoSLA15 }\end{array}$ & $\begin{array}{l}1.748 \\
(5.27)\end{array}$ \\
\hline $2^{\text {nd }}$ Child & $\begin{array}{l}-0.099 \\
(2.56)\end{array}$ \\
\hline $3^{\text {rd }}$ Child & $\begin{array}{l}-0.208 \\
(4.07)\end{array}$ \\
\hline $4^{\text {th }}$ Child & $\begin{array}{l}-0.408 \\
(7.57)\end{array}$ \\
\hline $5^{\text {th }}$ Child & $\begin{array}{l}-0.471 \\
(6.70)\end{array}$ \\
\hline $6^{\text {th }}$ or higher order child & $\begin{array}{l}-0.534 \\
(8.62)\end{array}$ \\
\hline Gestation days & $\begin{array}{l}0.002 \\
(1.82)\end{array}$ \\
\hline Gestation days missing & $\begin{array}{l}-0.100 \\
(2.61)\end{array}$ \\
\hline Dummies for maternal birth year & Yes \\
\hline Dummies for region of residence & yes \\
\hline Constant & $\begin{array}{l}17.175 \\
(37.36)\end{array}$ \\
\hline Observations & 8265 \\
\hline R-squared & 0.21 \\
\hline
\end{tabular}

Note: Linear regression of maternal years of education. Omitted categories are maternal grand dad social class I, mother born in 1921, North West region and first child born. Robust standard errors are used to compute the reported t-statistics in parentheses. 